\title{
Um modelo de leitura
}

\author{
Carla Viana Coscarelli \\ Mike Dillinger \\ UNIVERSIDADE FEDERAL DE MINAS GERAIS
}

\section{Abstract}

This paper proposes a model of reading processing based mainly on Fodor's (1983) theory of the modularity of the mind. According to this model there are many domains of processing in reading. Some of them are part of the linguistic module and others are part of the cognitive processor. Among the domains of the linguistic module there are lexical access and sintactic parsing. To build up the propositional scheme of a text and to integrate the propositional macrostructure of the text to the reader's previous knowledge are tasks of the cognitive processor. This model also proposes an interface between the linguistic module and the cognitive processor, where semantic parsing takes place. 


\section{INTRODUÇÃO}

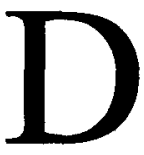

e acordo com Сномsкy (1988), as perguntas primordiais que uma teoria completa da linguagem teria que respon der são quatro:

(1) Qual a natureza do sistema de conhecimento lingüístico?

(2) Como é adquirido?

(3) Como é utilizado?

(4) Quais os mecanismos fisicos envolvidos na representação, aquisição e uso desse conhecimento?

Partindo destas perguntas, CARSTON (1988: 38) aponta traços básicos da visão mentalista da linguagem que tem implicações para o trabalho sobre os sistemas cognitivos em geral. Segundo ele, "essas perguntas devem ser abordadas dentro de uma visão geral da mente como um sistema de princípios computacionais, formando e transformando representaçðes; o conhecimento linguástico é um conjunto destes princípios computacionais e usá-lo envolve a interação destes princípios com outros sistemas de representação mental e computação".

As idéias acima são tomadas de FoDor (1983), que argumenta a favor da modularidade do sistema cognitivo, isto é, que esse sistema seja constituído de módulos ou subpartes independentes que possuem várias características em comum e juntos formam uma unidade maior, que é o sistema cognitivo. Segundo ele, só é possivel estudar o que é modular.

FODOR (1983) divide a mente humana em dois tipos principais de processamento: os sistemas de input e o processador cognitivo. De 
acordo com CARSTon (1988: 57), '”o maior tema de Fodor 1983 e 1985 é que os processos cognitivos centrais não são fáceis de serem investigados: enquanto o sistema de input tem status de problema, 0 sistema central tem status de mistério; podemos atacar problemas; os mistérios estão além de nós". FoDor propőe que a utilização da linguagem seja concebida como sendo uma interação entre um desses módulos e o processador cognitivo central. Além disso, defende que os limites da modularidade são provavelmente os limites do que será possivel entender sobre a mente.

O modelo de leitura que será apresentado aqui tem como um dos seus principais pilares essa teoria defendida por FoDOR (1983) a respeito da modularidade da mente. Por causa disto, as partes do modelo serão apresentadas juntamente com aspectos da teoria que serviram de base para sua construção. Nos parágrafos a seguir, o módulo lingüístico e o processador cognitivo central serão descritos para que se possa caracterizar com mais detalhes a interação entre eles.

\section{O MódULO LINGŨísTICO}

Segundo FodOR (1983), a função dos sistemas de input, entre eles o módulo lingüístico, é receber as estímulos que vêm de fora do organismo e que chegam a ele de formas distintas, através dos órgãos de percepção como a visão e a audição. Fodor apresenta uma lista de propriedades dos sistemas de input que os caracterizam como modulares:

. Os sistemas de input são específicos para determinado domínio de estímulos - Existem, nos aparelhos sensoriais (visão, audição, tato, olfato e paladar) e na linguagem, mecanismos altamente especializados. Podem-se citar, no caso da visão, por exemplo, os mecanismos para a percepção de cores, para a análise da forma e para a análise de relaçðes espaciais. Provavelmente existem muitos tipos de domínios cuja análise perceptual requer informação altamente especifica. Alguns exemplos de informaçðes específicas no caso da linguagem são a organização da percepção de sentenças em torno de informações fonéticas, fonológicas e sintáticas. 
- A operação dos sistemas de input é automática/compulsória - A operação dos sistemas de input parece ser independente da vontade do indivíduo. Um exemplo disso é que não se consegue deixar de ouvir um estímulo audível por interferência da vontade, a não ser tapando os ouvidos.

. Só há acesso limitado às representações mentais que os sistemas de input computam - Um sujeito não tem acesso igual a todos os níveis de representação da linguagem. As representações fonética, fonológica, lexical e sintática parecem ser completamente inacessíveis à consciência. Somente os outputs dos processadores perceptuais parecem ser de acesso livre para os processos cognitivos centrais, que são, em grande parte, conscientes. No caso da linguagem, é normal que o sujeito perca rapidamente as informaçøes a respeito dos detalhes da sintaxe ou do vocabulário, ficando apenas com o que ele considera importante, naquele momento, no texto.

. Sistemas de input são muito rápidos - Identificar sentenças e estímulos visuais está entre os mais rápidos processos psicológicos. Normalmente a análise perceptual de uma sentença ou cena é quase instantânea. Caso haja alguma dificuldade a ser resolvida, o tempo gasto para a resolução deverá ser de milésimos de segundo, ao passo que a resolução de um problema pelo processador cognitivo central pode levar minutos, horas, meses, etc.

. Sistemas de input são informacionalmente fechados - Compreender uma sentença envolve estabelecer análises desta sentença em vários níveis de representação: fonética, fonológica, lexical, sintática, etc. É possível que, durante o processamento da sentença, uma informação de um nível de representação considerada mais 'alto' seja usada para determinar análises de níveis considerados mais 'baixos', mas somente dentro do sistema de input. FoDor argumenta que as operaçбes dos sistemas de input não são afetadas pelo processador cognitivo, que é consciente. Isto quer dizer que o produto dos sistemas perceptuais é independente do que o sujeito supõe ou deseja. A limitação informacional dos sistemas de input é a essência da sua modularidade. . Sistemas de input têm um produto pouco trabalhado - O sistema de input da linguagem, por exemplo, especifica, para cada sentença, ape- 
nas a sua forma lingüística e talvez a sua forma lógica.

. Sistemas de input são associados a uma arquitetura neuronal fixa Parece haver uma arquitetura neuronal específica associada a cada sistema de input. $\mathrm{O}$ fato de esta arquitetura apresentar conexóes estruturais indica a existência de caminhos privilegiados de acesso informacional. $\mathrm{O}$ efeito dessa limitação facilita o fluxo de informação de uma estrutura neurológica para outra. Mas o que, por um lado, conta como relativa facilitação, por outro conta como limitação. Se o fluxo de informação de $\mathrm{A}$ para $\mathrm{B}$ é facilitado por uma conexão fixa entre eles, $B$ terá um tipo de acesso a $A$ que não terá com $C, D$, etc. Este tipo de acesso faz sentido para um sistema que quer acesso rápido e específico para $A$ e não para $C, D$, etc.

. Sistemas de input exibem padrões de disfunção ou patologia caracteristicos e específicos - Agnosias e afasias constituem falhas no funcionamento padrão, isto é, não podem ser explicadas por diminuição quantitativa de capacidades globais como memória, atenção e solução de problemas. Se a análise de inputs é afetada por restrições específicas ao circuito neurológico, as patologias dos sistemas de input são causadas por problemas nestes circuitos especializados.

. A ontogenia dos sistemas de input exibe velocidade e seqüência próprias - Grande parte dos sistemas de input são endogenamente determinados, isto é, são inatos. Os mecanismos neurológicos de análise de input desenvolvem-se de acordo com padróes específicos e endogenamente determinados, sob o impacto de 'gatilhos' ambientais.

Segundo FODOR (1983), para que um sistema seja considerado modular é preciso que ele tenha todas ou a maioria das propriedades acima.

O módulo lingüístico é, para ele, um dos módulos ou sistemas computacionais inatos, autônomos, involuntários e inconscientes que se caracterizam pela capacidade limitada de receber e armazenar informação, pela rapidez e pelo acesso restrito. Por acesso restrito entende-se que o usuário da linguagem não tem acesso às operações realizadas pelo módulo linguíístico, não podendo interferir em seu funcionamento. A função dos sistemas de input é alimentar o processador cognitivo central com informação ou estímulos do mun- 
do exterior.

Dois domínios de processamento fazem parte do módulo lingüístico: o acesso lexical e o parsing sintático.

\section{Acesso Lexical}

É neste domínio que as letras e palavras são percebidas visualmente pelo leitor como traços verticais, horizontais, circulares, etc. Ao reconhecer as palavras como pertencentes à sua língua ou possíveis nela, vários tipos de informação são ativados: informações fonológicas, fonéticas, sintáticas e semânticas (Foss, 1988). BALOTA (1990) defende que nos sistemas fonográficos, como, por exemplo, o português e o inglês, no mínimo três tipos básicos de informação são ativados durante o reconhecimento de uma palavra: o significado da palavra, o seu som e sua forma visual. Segundo ele, parece haver uma identificação visual anterior à análise do significado, isto é, algum nível de análise visual deve ser necessário e anterior ao acesso do significado.

De acordo com Balota, fatores como o número de ocorrências de uma determinada palavra e a familiaridade do leitor com ela facilitam o acesso lexical (BALOTA, 1990; Foss, 1988; GERUSBACHER, 1985, MASSARO, 1975).

O acesso lexical é uma das funções do módulo lingüístico e, como tal, é um processo automático e inconsciente, isto é, não sofre interferência voluntária do sujeito. Quando se escuta alguém falando, é difícil não reconhecer o que está sendo dito. Segundo MARSLEN-WILSON \& TYLER (1981, citado por Fodor, 1983: 53), "mesmo quando se pede aos sujeitos para focalizar a atenção em propriedades acústico-fonéticas do input, eles não parecem ser capazes de evitar a identificação da palavra envolvida. (...) Isso implica que o tipo de operações de processamento observáveis no reconhecimento de palavras faladas é mediado por processos automáticos que são obrigatoriamente aplicados". Portanto, um sujeito só não reconhecerá o que foi dito se concentrar a sua atenção em alguma outra coisa. Parece que o sistema de input continua funcionando, mas o acesso deste input ao processador cognitivo pode ser temporariamente cortado. 
$\mathrm{Na}$ leitura parece acontecer exatamente isso. Quando uma pessoa alfabetizada olha para uma palavra na sua língua, lê esta palavra mesmo 'sem querer'. A leitura só não acontecerá se o 'leitor' desviar a atenção (não necessariamente o olhar) para outra coisa. As informações fonológicas, fonéticas e sintáticas das palavras ativadas no acesso lexical são processadas em outro domínio de processamento: o parsing sintático.

\section{Parsing Sintático}

As informaçбes resultantes do acesso lexical vão possibilitar a construção da estrutura sintática das frases - o parsing sintático. A construção da estrutura sintática dos sintagmas ou frases parece ser feita, num primeiro momento, sem se levar em consideração o conteúdo semântico deles (ClarK \& ClarK, 1977; FERREIRA \& ClIFToN, 1986).

Frazier, Clifton \& Randall (1983) acreditam que uma representação da estrutura de superfície da sentença é construída rapidamente usando informações como categoria lexical e possíveis estruturas de frase da língua. No caso de ambigüidade, cabe ao processador cognitivo decidir sobre qual das possíveis representações de uma sentença será usada.

Em certa época, muitos autores, como, por exemplo, GougH (1972), consideravam que o processo de leitura terminava neste ponto. A leitura era vista como decodificação de sinais gráficos e organização das estruturas sintáticas das sentenças. Tais modelos de leitura transmitem a idéia de que para compreender textos basta ao leitor fazer a decodificação mecânica de sentenças isoladas - que não envolve a representação semântica do texto. Nesta perspectiva, o texto é visto, implicitamente, como um amontoado de sentenças, ao invés de ser visto como uma unidade coerente de significado. De acordo com BeLLERT (1970), o que diferencia um texto de um amontoado de sentenças é a presença de conectividade entre as idéias (coerência) e entre as orações e sentenças (coesão). Textos ambíguos, como o exemplo abaixo, ilustram bem esta situação na qual compreender cada palavra ou frase separadamente não é suficiente para a compreensão do 
texto e assim ilustram um tipo de problema que tais teorias não conseguem resolver.

Depois que a professora devolveu o caderno para a menina, ela deu um sorriso.

Nessa sentença não é possível saber com certeza quem deu o sorriso, se foi a professora ou a menina. As duas interpretações são possíveis, pois o pronome ela permite como antecedente tanto uma quanto a outra.

Outros exemplos, em que estabelecer a relação entre as sentenças é importante, são os casos de elipse ou elementos que podem ser omitidos do texto por serem recuperáveis através do uso do contexto lingüístico, como os seguintes:

. Paulo comeu pizza. Maria, Ø macarrão.

. Paulo saiu de casa cedo. Ø Está treinando futebol.

No primeiro exemplo, o verbo comer está elíptico na segunda oração, já que é facilmente recuperável. A repetição desse verbo seria redundante e desnecessária, pois, mesmo não estando explícito, é pouco provável que algum leitor preencha essa lacuna com outro verbo diferente de comer. Já no segundo exemplo, houve a elipse do sujeito Paulo. Pelo fato de se estar falando somente de Paulo seria muito estranho pensar que quem está treinando é uma outra pessoa.

Nos exemplos acima, se não houver a leitura do 'texto', ou seja, se não for feita a ligação entre as idéias das diferentes sentenças, as frases tornam-se incompreensiveis. Isso mostra as deficiências de uma concepção que iguala e restringe a 'leitura' à 'decodificação' : tal concepção não tem como abordar esses fenômenos.

No parsing sintático é construída a estrutura sintática das sentenças. Este domínio é, como o acesso lexical, parte do módulo lingüistico, portanto, rápido, especializado, independente de outros tipos de processamento, etc. Do próximo domínio de processamento, parsing semântico, em diante o processador cognitivo começa a ser 
ativado.

O módulo lingüístico, portanto, fornece rápida e automaticamente informações sobre as palavras da frase e as relações formais/sintáticas entre elas. $O$ processador cognitivo retrabalha essas informações para elaborar um significado para as frases do input.

\section{A INTERFACE ENTRE O MÓDULO LINGUUISTICO E O PROCESSADOR COGNITIVO}

FODOR (1983) acredita que a linguagem se dá através da interação entre o módulo lingüístico e o processador cognitivo, e admite que não se sabe muito sobre como esta interação acontece.

Feito o parsing sintático, ou seja, identificada a estrutura sintática da sentença e dos seus constituintes, o leitor constrói uma ou mais unidades de significado (proposições) para cada sentença ou para suas partes. Depois disso, a estrutura superficial da sentença é tirada da memória, ficando disponível somente o significado e não mais a forma literal (CLARK \& CLARK, 1977).

Nessa ótica, BRANSFORD, BARCLAY \& Franks (1972) sugerem que as sentenças não devem ser vistas como objetos linguiísticos a serem lembrados, mas como informações que os sujeitos podem usar para construir descrições semânticas. Essas descriçб̋es podem conter mais informação do que está representado no input lingüístico e, portanto, uma análise puramente lingüística do input não vai caracterizar adequadamente a informação construída pelo leitor.

Alguns elementos de um texto, como os elementos coesivos nominais, só parecem ser analisados numa 'área limítrofe' ou interface entre o módulo lingüístico e o processador cognitivo. Nessa interface, postula-se um domínio de processamento, o parsing semântico, no qual as informaçóes fornecidas pelo módulo lingüístico são processadas.

\section{Parsing Semântico}

O parsing semântico é a parte do domínio de processamento na qual se dá o encontro ou a interface entre o módulo lingüístico e o 
processador cognitivo. É esse o domínio no qual se postula a construção de proposiçбes a partir das estruturas sintáticas do texto. 'Proposições', no sentido usado pela psicologia cognitiva (FrEDERIKSEN et alii, 1990; KINTsCh \& VAN DIJK, 1978), são constituídas de um predicador e um ou mais argumentos e servem tanto para representação da informação conceitual do texto, quanto como unidades de informação para raciocínio lógico e solução de problemas (FREDERIKSEN, 1975). Assim, as proposiçð̋es constituem as unidades básicas do processamento cognitivo.

A construção de proposições a partir da estrutura sintática da sentença é uma das atividades da interface entre o módulo lingüístico e o processador cognitivo. A interface recebe do módulo lingüistico informaçð̃es fonéticas, fonológicas, lexicais e sintáticas a respeito das frases lidas. Cabe ao parsing semântico gerar as proposiçб̃es correspondentes às frases, isto é, fazer a análise semântica das frases e das relaçð̃es entre elas.

O resultado do parsing semântico são proposiçóes a partir das quais será construída, pelo processador cognitivo, a estrutura semântica do texto.

As proposiçzes parecem ser construídas pelo leitor a partir do texto e de suas experiências sobre aquele assunto. $O$ significado de uma determinada palavra, por exemplo, "não é representado simplesmente como uma lista de traços semânticos isolados ou prototípicos, mas deve ser concebido como um conjunto de experiências individuais com aquela palavra. Cada uma das experiências contribui para o desenvolvimento do significado que atribuímos àquela palavra" (BALOTA, 1990: 26). Isso quer dizer que as proposiçðes podem também ser inferidas no processador cognitivo, ou seja, o leitor usa seu conhecimento sobre aquele assunto para preencher lacunas que freqüentemente são deixadas pelas sentenças do texto. Um exemplo disso é o texto abaixo:

Vou à Brinquedolândia agora. Amanhã é o aniversário do colega do Paulinho. 
Esse texto vai parecer completamente sem lógica para quem não souber que no Brasil os colegas costumam dar presentes ao amigo aniversariante. Também não vai entender o texto quem não for capaz de inferir que Paulinho e seu colega são crianças e que Brinquedolândia é uma loja de brinquedos.

Um dos tipos de inferências textuais muito importante é a recuperação dos antecedentes dos elementos coesivos nominais. Dado que a coesão nominal ocorre quando se utiliza, no texto, um elemento cuja determinação da referência depende de outro elemento introduzido alhures no texto (SANFORD \& GARROD, 1981), a compreensão dos elementos coesivos nominais depende de o leitor encontrar, no próprio texto ou na sua representação mental do texto, as entidades 'antecedentes' - aos quais esses elementos se referem. No trabalho de processar a coesão nominal do texto, cabe ao leitor estabelecer as relações entre o elemento coesivo nominal e o seu antecedente, como pode ser visto no exemplo abaixo:

Antônio foi à padaria e até agora o demônio não voltou. Aposto que está jogando fliperama ... Aquele anjinho só fala mentira. Outro dia ele ...

Ao ler o texto acima, o leitor precisa relacionar os elementos Antônio, demônio, $\mathscr{Q}$, anjinho e ele a um mesmo referente - aquele determinado indivíduo cujo nome é Antônio. Só assim o texto fará sentido. Esse é também mais um exemplo de que não basta ler as palavras, é preciso estabelecer as relações entre os termos dentro da sentença e entre as sentenças, mesmo que elas não sejam explícitas. Em suma, é papel do leitor construir o significado do texto a partir das 'dicas' fornecidas pelo texto. Em outras palavras, é preciso haver constante interação entre módulo lingüístico e processador cognitivo 
para que haja realmente leitura.

\section{O PROCESSADOR COGNITIVO}

É no processador cognitivo que são recebidas e processadas, no nível semântico, as informações proposicionais a ele fornecidas pelo módulo lingüístico e pela interface. Ao contrário do módulo lingüístico, o processador cognitivo é um sistema computacional em grande parte voluntário e consciente, isto é, boa parte do que é feito no processador cognitivo depende da vontade do sujeito, que pode interferir em muitas de suas operações.

O processador cognitivo não apresenta as características necessárias para ser considerado modular. Ao contrário do que se espera de um módulo, uma operação do processador cognitivo é, de modo geral, voluntária; não parece haver muitas limitações às operações realizadas pelo processador cognitivo; as operaçóes realizadas no processador cognitivo têm velocidade variável dependendo do grau de dificuldade do problema; e, além disso, não parece haver estrutura neurológica fixa para ele. FoDOR (1983: 107) defende que muitos processos cognitivos, como o raciocínio analógico, "dependem da transferência de informação entre domínios cognitivos antes tidos como mutuamente irrelevantes". Por ser um mecanismo no qual se processam informações provenientes de diversos domínios e no qual podem ser feitas analogias e inferências de outros tipos, pode-se dizer que o processador cognitivo não é 'fechado' informacionalmente e que, portanto, é provável que a maior parte dos mecanismos cognitivos não seja específica deste ou daquele domínio.

O parsing semântico - interface entre o módulo lingüístico e o processador cognitivo - fornece ao processador cognitivo uma análise semântica preliminar das frases, para que este possa estabelecer, por operaçð̃es chamadas 'inferências' (feitas a partir dessas informações) a coerência do texto. A coerência é a rede de relações entre conceitos e proposiçóes (FraN̦CIs, 1986) responsável pela çontinuidade de sentido no texto.

Inferências 
Muitas vezes a informação lingüística explícita no texto não é suficiente para que se construa a coerência. Nesses casos, o leitor será obrigado a fazer inferências. Inferências são operações cognitivas em que o leitor constrói proposiçøes novas a partir de informações que ele encontrou no texto. Porém, as inferências não ocorrem apenas quando o leitor estabelece ligaçðes entre as palavras e organiza redes conceituais no interior do texto. Ocorrem, também, quando o leitor busca fora do texto informaçóes e conhecimentos adquiridos pela sua experiência de vida, com os quais preenche os 'vazios' textuais. Grosso modo, inferências servem para preencher os 'buracos' deixados no texto (Dell'Isola, 1991).

Um exemplo de inferência é o que se faz quando numa estrada se encontra uma placa dizendo: 'Pare fora da pista'. Essa placa não é normalmente interpretada como uma ordem para o motorista parar naquele local, embora isso seja possível caso o leitor nada saiba sobre sinais de trânsito. Quem conhece os sinais de trânsito usa esse conhecimento para interpretar essa placa como sendo um aviso de que, caso ele queira ou precise parar, deve fazê-lo no acostamento. Essa informação adicional é relacionada ao texto da placa por inferência.

Outro exemplo, desta vez de inferências pragmáticas (LEVINSON, 1983), são os atos indiretos de fala, como os casos abaixo:

\section{Você tem horas?}

Você quer passar o sal para mim?

Respostas 'sim' ou 'não' nesses casos seriam absurdas, devido à capacidade que os usuários da língua têm de fazer inferências. Quando se ouvem ou se lêem frases como essas infere-se imediatamente que a pessoa quer saber quantas horas são ou quer que alguém passe o sal para ela - são pedidos indiretos. Certamente ninguém vai pensar que a pessoa que perguntou quer saber se ela tem ou não relógio ou se ela deseja ou não passar o sal.

As inferências feitas pelo leitor durante a leitura tornam-se parte da representação mental do texto como qualquer outra das proposi- 
ç⿸尸es originais deste (KINTSCH \& VIPOND, 1979; SANFORD \& GARROD, 1981).

\section{Construção de Esquemas}

Um dos domínios de processamento que fazem parte do processador cognitivo é o da construção dos esquemas. Aqui o leitor relaciona as proposições entre si, construindo com elas uma representação semântica do texto (esquema ou macroestrutura - KINTSCH \& VAN DIK, 1978; KINTSCH \& VIPOND, 1979). Essa rede ou estrutura de proposiçôes pode ser organizada de diversas maneiras pelo leitor, privilegiando-se informações estruturais, como o status de tópico ou não-tópico dos elementos do texto ou informações de tipos específicos como, por exemplo, a estrutura temporal dos eventos do texto. Isto quer dizer que, quando alguém lê um romance simplesmente para saber a estória, este leitor pode organizar as proposições do texto, ou construir um esquema, de uma forma diferente daquela pessoa que lê o texto para conhecer hábitos e costumes de determinada época; que, por sua vez, pode ser diferente do esquema construído pelo leitor que está interessado, por exemplo, no estudo das características psicológicas dos personagens.

Neste domínio de processamento é construída a macroestrutura proposicional do texto a partir das proposições retiradas do texto ou inferidas pelo leitor.

A Integração de Macroestruturas Proposicionais do Texto aos Conhecimentos Prévios do Leitor

Em outro domínio de processamento envolvido na leitura ocorre, ainda, a integração de macroestruturas proposicionais do texto aos conhecimentos prévios do leitor. Entende-se como conhecimento prévio ou conhecimento de mundo as diversas informações sobre todos os assuntos que o leitor tem na memória de longo prazo (SMTH, 1978).

Parece ser neste domínio que as eventuais informações novas introduzidas pelo texto no processo de leitura modificam (ou não) os conhecimentos prévios do leitor. Como resultado dessa integração pode-se ter o conhecimento revisto do leitor, isto é, acrescido e/ou 
modificado pelas informações introduzidas pelo texto.

O uso do conhecimento prévio permite ao leitor fazer deduções que preencham as lacunas deixadas pelo texto e que estabeleçam as relaçốes entre as sentenças do texto; além disso, fornece o contexto necessário para a interpretação das informações do texto (JORM, 1986). Se, por exemplo, a uma pessoa que nada sabe de física for dado um texto técnico de física nuclear, praticamente não haverá compreensão. Isso acontece porque aquele leitor não dispõe do conhecimento prévio necessário à leitura daquele texto. Por outro lado, o leitor não precisa conhecer todas as palavras de um texto para entendê-lo. No caso de encontrar palavras ou expressões desconhecidas, o leitor maduro geralmente lança mão do seu conhecimento prévio e do contexto lingüístico para dar sentido a essas palavras, procurando fazer com que elas não prejudiquem a compreensão do texto.

É importante ressaltar que o conhecimento prévio do leitor está presente em todo o processo de leitura. Para que a leitura seja bem sucedida, o leitor precisa usar seus conhecimentos a respeito da língua e a respeito da sua utilização em todos os domínios de processamento. Também o conhecimento prévio do leitor a respeito do assunto tratado no texto (e de outros assuntos) se faz necessário na leitura. Podem-se citar, por exemplo, as muitas vezes em que os textos não favorecem a percepção das relações entre seus elementos. $O$ conhecimento prévio torna-se, então, fundamental, pois possibilita ao leitor fazer inferências, ou seja, construir as pontes necessárias para estruturar o texto aduzindo informações a que este não remete explicitamente (FULGENCIO \& LIBERATO, 1992).

\section{COESÃO E COERÊNCIA}

Assim, vê-se que a habilidade de relacionar informações que vêm de diferentes constituintes textuais é uma parte muito importante da compreensão da linguagem. Parece haver um subconjunto dos processos e recursos que constituem a compreensão, que fornece os recursos para armazenar informações dos constituintes precedentes ao que está sendo lido, enquanto simultaneamente fornece os recursos 
computacionais para processar os constituintes subseqüentes (JUST \& CARPENTER, 1992).

A coesão pode ser vista como o conjunto de recursos lingüísticos que ajudam o leitor a estabelecer a coerência entre as idéias do texto. São recursos linguísticos que assinalam uma ligação entre uma sentença e o que veio antes, por exemplo, através de elementos no texto cuja interpretação depende de outros, como acontece com os pronomes, por exemplo:

\section{Paulo saiu, mas ele disse que 0 não vai demorar.}

No exemplo acima, só é possível saber quem é ele se o leitor conseguir estabelecer a relação entre o pronome e uma entidade já mencionada no texto, no caso, Paulo. Essa relação de dependência referencial de elementos coesivos nominais com elementos previamente introduzidos no texto é uma das situaçбes em que é preciso relacionar informaçס̃es de diferentes constituintes.

Para HallidaY \& Hasan (1976), a coesão é um meio lingüístico pelo qual um texto passa a funcionar como uma unidade significativa. É ela que sinaliza lingüisticamente as relações entre os elementos do texto.

Certos tipos de coesão, segundo Koch (1990), podem não ser suficientes para que um texto seja considerado um texto, mas costumam dar maior legibilidade a ele já que normalmente explicitam as relaçбes estabelecidas entre os elementos lingüísticos que o compøem. Portanto, a coesão é, na maioria dos casos, necessária como mecanismo de sinalização superficial da coerência.

Enquanto a coesão é uma rede de relações entre os elementos do texto, a coerência é uma rede de relaçð̃es entre os elementos conceptuais do significado do texto (FrancIs, 1986). A coesão é explicitamente assinalada - são marcas lingüísticas de superficie - ao contrário da coerência, que é subjacente ou inferida (Koch \& TravaGLia, 1990).

Há entre a coesão e a coerência uma relação paralela àquela existente entre o módulo lingüístico e o processador cognitivo. $O$ módulo 
lingüístico fornece ao processador cognitivo informações lingüísticas derivadas do acesso lexical e do parsing sintático. No processador cognitivo, por sua vez, ocorre a construção do significado. $O$ mesmo acontece com a coesão e a coerência. A coesão pode ser vista como um input que fornece dados lingǘsticos ao processador cognitivo, no qual será construída a coerência do texto.

Pode-se perguntar, então, o que aconteceria com os textos que não trazem explícitos os elementos linguísticos coesivos, como é o caso, por exemplo, do trecho abaixo, tirado do poema de Affonso Romano de Sant'Anna (citado por BIANCHINI \& CUNHA, 1981:210):
A PESCA
$O$ anil
$O$ anzol
$O$ azul
O silêncio
O tempo
O peixe
A agulha
vertical
mergulha
A água
A linha
A espuma
O tempo
Opeixe
O silêncio
(...)

Se é através dos elementos coesivos que se estabelece a coerência do texto, naquele em que não há elementos coesivos explícitos haverá coerência? Como são compreendidos os textos em que não há elementos coesivos explícitos? Nos casos como o do poema "A pesca", o processador cognitivo vai desempenhar um papel maior do que o módulo lingüístico: o fato de o input lingüistico não trazer ex- 
plícitas as relações entre os elementos do texto exigirá que o leitor faça inferências para estabelecer as ligações entre eles e assim 'compensar' a falta de informações no texto.

Vê-se, então, que em muitas situaçð̃es o processador cognitivo atua para compensar falhas do módulo lingüístico ou do texto, baseando-se em informações sobre o assunto, o contexto, etc.

\section{CONCLUSĀo}

A leitura, em suma, envolve diversos domínios de processamento, variando da percepção visual das letras até a integração de macroestruturas proposicionais do texto aos conhecimentos prévios do leitor. Para fins de exposição, esses domínios foram apresentados um após o outro como se fossem passos seriados. Durante algum tempo, acreditava-se que a leitura passava seqüencialmente por todos estes domínios, um após o outro (FoDor et alii, 1974), mas é possível que não seja preciso passar por todos os domínios de processamento em uma ordem preestabelecida. Pode ser que todos, ou pelo menos alguns, ocorram paralelamente (FREDERIKSEN, 1990; KINTSCH \& VAN DIJK, 1978).

Destes domínios de processamento, o acesso lexical e o parsing sintático claramente fazem parte do módulo lingüístico. A construção de esquemas e a integração de macroestruturas proposicionais do texto aos conhecimentos prévios do leitor são domínios que claramente fazem parte do processador cognitivo. Os limites entre o módulo lingüístico e o processador cognitivo coincidem com o parsing se- 
mântico, como pode ser visto no quadro abaixo:

\begin{tabular}{|c|c|}
\hline $\begin{array}{l}\text { Componentes da Capacidade } \\
\text { Comunicativa }\end{array}$ & Dominios de Processamento \\
\hline Módulo Lingứstico & $\begin{array}{l}\text { Acesso Lexical } \\
\text {. Parsing Sintático }\end{array}$ \\
\hline INTERFACE & . Parsing Semântico \\
\hline Processador Cogmitivo & $\begin{array}{l}\text { Construção de Esquemas } \\
\text {. Integração das Macroestruturas } \\
\text { Proposicionais do Texto aos } \\
\text { Conhecimentos Prévios do } \\
\text { Leitor }\end{array}$ \\
\hline
\end{tabular}

Desta forma, entre os elementos textuais que são processados nos limites entre o módulo linguístico e o processador cognitivo, podese citar a coesão. Portanto, o estudo de elementos coesivos pode contribuir para esclarecer a interface entre o módulo lingüístico e o processador cognitivo.

\section{REFERÊNCIAS BIBLIOGRÁFICAS}

Balota, D. A. The role of meaning in word recognition. In: BALOtA, D. A., Flores

D'ARCAIs, G. B. \& RAYNER, K. (eds.), Comprehension processes in reading. Hillsdale: Lawrence Erlbaum, 1990. p.9-32.

BeLLeRT, I. On a condition of the coherence of texts. Semiotica, 4, 1970. p.335-363. Bianchin, O. \& Cunha, M. A. A. Nos domínios da linguagem: Comunicação e expressão e elementos de educacão artística: $7^{\mathfrak{a}}$ série. São Paulo: FTD, 1981. Carston, R. Language and cognition. In: NewMEYER, F. J. (ed.), Linguistics: The Cambridge Survey: Vol. 3. Language: Psychological and biological aspects. Cambridge: Cambridge University Press, 1988. p. 38-68.

Chomsky, N. Language and problems of knowledge: The Managua lectures. Cambridge, MA: MIT Press, 1988.

Clark, H. H. \& ClaRK, E. V. Psychology and language. New York: Hardcourt Brace Jovanovich, 1977. 
DeLL'IsolA, R. L. P. Leitura: inferências e contexto sócio-cultural. Belo Horizonte: Imprensa Universitária, 1991.

FerReIrA, F. \& Clifton, C. Jr. The independence of syntatic processing. Journal of Memory and Language, 25, 1986. p.348-368

FoDOR, Jerry A. The modularity of mind. Cambridge. MA: MIT, 1983.

FODOR, J., BEVER, T., GARRETT, M. The Psychology of language: An introduction to Psycholinguistics and Generative grammar. New York: McGraw-Hill, 1974.

Foss, D. J. Experimental Psycholinguistics. Annual Review of Psychology, 39, 1988. p.301-348.

FranCIS, G. Anaphoric Nouns. Birmingham: ELR, 1986.

Frazier, L., Clufton, C. \& RaNdall, J. Filling gaps: Decision principles and structure in sentence compreension. Cognition, 13, 1983. p.187-222.

FREDERIKSEN, Carl H. Representing logical and semantic structure of knowledge aquired from discourse. Cognitive Psychology, 7, 1975. p.371-458.

Frederiksen, C. H., Bracewell, R., Brenleux, A. \& Renaud, A. The cognitive representation and processing of discourse: Function and dysfunction. In: JOANELLE, Y. \& BrowELL, H. H. Discourse ability and brain damage. New York: Springer-Verlag, 1990. p.68-110.

Fulgencto, L. \& Liberato, Y. Come facilitar a leitura. São Paulo: Contexto, 1992.

GERUSBACHER, M. A. Resolving 20 years of inconsistent interactions between lexical familiarity and orthography, concreteness, and polysemy. Journal of Experimental Psychology, 113 (3), 1985. p.256-281.

Gough, P. B. One second of reading. In: KaVANaGh, J. F. \& MatTINGLY, I. G. (eds.). Language by ear and by eye: The relationships between speech and reading. Cambridge, MA: MIT Press, 1972.

HallidaY, M. A. K. \& Hasan R. Cohesion in English. London: Longman, 1976.

JoRM, A. F. Psicologia das dificuldades em leitura e ortografia. Porto Alegre: Artes Médicas, 1986.

JUST, A. M. \& CARPENTER, P. A. A capacity theory of comprehension: Individual differences in working memory. Psychological Review, 99 (1), 1992. p.122149.

KINTSCH, W. \& VAN Dux, T. A. Toward a model of text compreension and production. Psychological Review, 85 (5), 1978. 363-394.

KINTSCH, W. \& VIPOND, D. Reading compreension and readability in educational practice and psychological theory. In: NusoN, L. G. (ed.), Perspectives on memory research . Hillsdale, NJ: Lawrence Erlbaum, 1979. p.329-65.

Koch, Ingedore V. A coesão textual. São Paulo: Contexto,1990.

Koch, I. V. e Travaglia, L. C. A coerência textual. São Paulo: Contexto, 1990.

Levinson, S. C. Pragmatics. Cambridge: Cambridge University Press, 1983.

Massaro, D. W.(org.), Understanding language. New York: Academic Press, 1975.

SANFORD, A. J. \& GARROD, S. C. Understanding written language. Chichester: John Wiley \& Sons, 1981.

SMTrH, Frank. Understanding reading. New York: Holt, Rinehart and Winston, 1978. 